\title{
Weight resilience and fruit and vegetable intake among African-American women in an obesogenic environment
}

\author{
Sara M Parisi ${ }^{1, *}$, Lisa M Bodnar ${ }^{1,2,3}$ and Tamara Dubowitz ${ }^{4}$ \\ 'Department of Epidemiology, Graduate School of Public Health, University of Pittsburgh, 130 Desoto Street, \\ 3602 Fifth Avenue Office, Pittsburgh, PA 15261, USA: ${ }^{2}$ Department of Obstetrics, Gynecology, and Reproductive \\ Sciences, School of Medicine, University of Pittsburgh, Pittsburgh, PA, USA: ${ }^{3}$ Magee-Womens Research Institute, \\ Pittsburgh, PA, USA: ${ }^{4}$ RAND Health, RAND Corporation, Pittsburgh, PA, USA
}

Submitted 3 April 2017: Final revision received 14 July 2017: Accepted 3 August 2017: First published online 10 0ctober 2017

\begin{abstract}
Objective: To investigate relationships between weight resilience (maintaining a normal weight in a food desert environment) and fruit and vegetable (F\&V) intake, attitudes and barriers.

Design: Cross-sectional, in-person surveys collected May-December 2011, including self-reported data on F\&V-related psychosocial factors, attitudes and barriers. Two $24 \mathrm{~h}$ dietary recalls were completed; weight and height were measured. Multivariable regression models estimated prevalence ratios (95\% CI). Setting: Two low-income, predominantly African-American food deserts in Pittsburgh, Pennsylvania, USA.

Subjects: Women aged 18-49 years ( $n$ 279) who were the primary food shopper in a household randomly selected for a parent study.

Results: Fifteen per cent were weight resilient, 30\% were overweight and 55\% were obese. Overall, $25 \%$ reported eating $\geq 5 \mathrm{~F} \& \mathrm{~V}$ servings/d. After adjustment for age, education, parity, employment, living alone, physical activity, per capita income and mean daily energy intake, women eating $\geq 5 \mathrm{~F} \& \mathrm{~V}$ servings/d were $94 \%$ more likely to be weight resilient compared with those eating $<5$ servings $/ \mathrm{d}$ (1.94; 1.10, 3.43). Across BMI groups, self-efficacy regarding F\&V consumption was high and few F\&V barriers were reported. The most frequently reported barrier was concern about the cost of F\&V (36\%). Of the attitudinal F\&V-related factors, only concern about wasting food when serving F\&V was associated with weight resilience in adjusted models (0.29; 0.09, 0.94). In a model predicting consuming $\geq 5 \mathrm{~F} \& \mathrm{~V}$ servings/d, driving one's own car to the store was the only attitudinal F\&V-related factor associated with consumption (1.50; 1.00, 2.24).

Conclusions: In this population, weight resilience may be encouraged by improving access to affordable and convenient F\&V options and providing education on ways to make them palatable to the entire household, rather than by shifting women's F\&V perceptions, which are already positive.
\end{abstract}

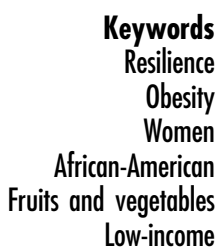

Resilience

Obesity

Women

vegetables

Low-income
Many low-income, African-American women live in neighbourhoods that are obesogenic 'food deserts' with limited access to fresh fruits and vegetables (F\&V), easy access to packaged or processed goods and an abundance of fastfood options ${ }^{(1,2)}$. Yet a portion of the women in these neighbourhoods are 'weight resilient' ${ }^{(3,4)}$, maintaining a healthy BMI despite living in an environment that encourages unhealthy eating and physical inactivity. The factors that support weight resiliency in low-income populations are not well understood and are likely to differ across sub-populations by race/ethnicity, gender and stage of life.

An understanding of weight resiliency in African-American women is particularly important because, currently in the
USA, $57 \%$ of this population are obese $\left(\mathrm{BMI} \geq 30 \cdot 0 \mathrm{~kg} / \mathrm{m}^{2}\right)$ compared with just over a third of non-Hispanic white women and African-American men ${ }^{(5)}$. Obesity is associated with higher rates of diabetes, CVD, musculoskeletal pain and other morbidity in women ${ }^{(6)}$, and presents both fertility challenges ${ }^{(6,7)}$ and increased risk of contraceptive failure $^{(8)}$. Reducing obesity in reproductiveaged women has the potential for wide-reaching maternal and child health impacts ${ }^{(9)}$ via improvements in birth outcomes $^{(10,11)}$, postpartum weight retention ${ }^{(12,13)}$, fetal programming $^{(14,15)}$ and cultural programming of healthy habits and attitudes. Women are often the food gatekeepers of a household and make purchasing and food 
preparation decisions that affect not only their health but also that of the entire family ${ }^{(16)}$. As a group, reproductiveaged women are also likely to face unique hormonal/ metabolic and day-to-day life challenges which make them a distinct and important population in which to study weight resilience.

Diets high in F\&V are associated with better overall health outcomes and a lower risk of many chronic diseases ${ }^{(17,18)}$, but there remains conflicting evidence on the association between F\&V intake and BMI, with some studies suggesting an inverse association ${ }^{(19-21)}$ and others finding no association $^{(17,22-24)}$. These conflicting findings are likely due in part to an underappreciation for the complex interplay of environmental, cultural, interpersonal and individual-level factors that work together to affect both weight and F\&V consumption. Increasing $\mathrm{F} \& \mathrm{~V}$ consumption has been a Healthy People objective since $1990^{(25)}$, but despite considerable efforts, consumption among US adults remains well below recommended guidelines ${ }^{(26,27)}$, with residents of low-income neighbourhoods reporting particularly low F\&V intake ${ }^{(28-31)}$. Most large studies of BMI and F\&V intake have been performed in primarily white, middle-class cohorts, limiting generalizability. Furthermore, the relationship between F\&V intake and obesity is confounded by socioeconomic status ${ }^{(29)}$. Focusing on female African-American women of reproductive age living within a defined low-income, food desert environment controls for many of these hard-to-measure sociocultural and environmental confounders, allowing us to gain a deeper understanding of the relationships between weight resilience and F\&V and related factors in this particular high-risk population.

To date, two studies have explicitly investigated factors associated with weight resilience in low-income, female populations, but one took place in Australia with a primarily white, reproductive-aged population ${ }^{(24)}$ (i.e. the READI study) and the other studied a small US population of African-American adolescents ${ }^{(21)}$. These two studies found conflicting results with regard to F\&V intake; the US study of adolescents did find a relationship between F\&V intake and BMI, but the Australian study did not. Both studies took a wide-lens look at weight resilience and used existing social ecological models for obesity ${ }^{(32,33)}$ and the three levels of the resilience framework developed by Garmezy $^{(34)}$ as their foundation, incorporating individual-, family/social- and extrafamilial (i.e. environmental, community)-level measures of healthy eating and physical activity into their analyses. But neither study asked more in-depth questions specific to $\mathrm{F} \& \mathrm{~V}$ attitudes, barriers or awareness, or examined their relationship with $F \& V$ intake and, in turn, with weight resilience. We designed our analysis with the same social ecological models/resilience framework principles in mind, but with an explicit focus on $\mathrm{F} \& \mathrm{~V}$ intake and related psychosocial factors. Individual-level cognitive factors shown to be related to a healthy BMI and F\&V intake include nutrition knowledge ${ }^{(35,36)}$ and self-efficacy for healthy eating ${ }^{(36-38)}$.
Self-efficacy measures the confidence in one's ability to perform specific behaviours in the future. Perceived barriers to $\mathrm{F} \& \mathrm{~V}$ intake are thought to be a key psychosocial factor and can be interpreted as both an individual-level factor as well as a social factor, as the other members of the household inform the household food purchaser's perceptions. Commonly reported barriers to $\mathrm{F} \& \mathrm{~V}$ intake include cost, time, concerns about wasting food or that no one in the household will eat the prepared food, not knowing how to prepare vegetables in an appealing way and motivation to prepare meals with vegetables ${ }^{(39-41)}$. On a community-wide level, it has been hypothesized that $\mathrm{F} \& \mathrm{~V}$ intake is associated with the offerings of $\mathrm{F} \& \mathrm{~V}$ at local grocery stores and access to full-service stores that sell quality produce ${ }^{(2)}$. However, many behaviour-based intervention studies have failed to show that improving self-efficacy, perceptions and awareness of recommendations for F\&V consistently increases F\&V intake ${ }^{(42)}$, so the strength of the association between psychosocial factors and F\&V intake, and ultimately weight resilience, remains unclear.

The objectives of the present study were: (i) to describe a population of low-income, reproductive-aged AfricanAmerican women living in food desert in terms of their sociodemographic characteristics, BMI and F\&V intake; and (ii) to investigate the association between weight resilience and F\&V intake, as well as with awareness, selfefficacy and barriers related to F\&V intake, in this population. We hypothesized that higher F\&V intakes would be associated with weight resilience. We further hypothesized that higher levels of self-efficacy, greater awareness regarding the recommended $\mathrm{F} \& \mathrm{~V}$ servings, and fewer physical and psychosocial barriers to buying/serving/ consuming F\&V would be positively associated with F\&V intake itself within this controlled neighbourhood context.

\section{Methods}

\section{Study design}

The present study used a subset of baseline data from the Pittsburgh Hill/Homewood Research on Eating, Shopping and Health (PHRESH) study, the details of which have been described previously ${ }^{(43-45)}$. In short, PHRESH was designed to evaluate the impact of opening a new full-service supermarket in an urban food desert on residents' food purchasing behaviours and diet. The study is set in two predominantly African-American low-income communities deemed to be food deserts, which the US Department of Agriculture defines as being both lowincome (poverty rate $20 \%$ or greater, or a median family income at or below $80 \%$ of the area median family income) and having low access to a supermarket (at least 500 persons or $33 \%$ of the census tract's population lives more than $1.6 \mathrm{~km}$ (1 mile) from a grocery store $)^{(46)}$. The two selected neighbourhoods were densely populated 
and were sociodemographically and geographically matched (Hill district: comprises six census tracts, $3.55 \mathrm{~km}^{2}$ (1.37 square miles) and a population of $\sim 10219$; Homewood: comprises seven census tracts, $3.76 \mathrm{~km}^{2}$ (1.45 square miles) and a population of $\sim 8300$ ). As previously reported, the nearest full-service grocery store was $2.4 \mathrm{~km}$ away, on average, and the nearest store that sold any type of food products was $0.4 \mathrm{~km}$, on average, from home ${ }^{(44)}$. Households were randomly selected for participation using a complete list of residential addresses generated from the Pittsburgh Neighborhood and Community Information System at the Center for Social and Urban Research at the University of Pittsburgh. Between May and December 2011, data collectors conducted in-person interviews with the primary household food purchaser, which included surveys, height and weight measurements, and a $24 \mathrm{~h}$ dietary recall. A second dietary recall was collected approximately a week later over the telephone. Participants received \$US 25 for completing the survey and first dietary recall and an additional \$US 15 for completing a second dietary recall. All study protocols were approved by Human Subjects Protection Committees representing both institutions of the authors.

Of the 1372 individuals who completed baseline surveys and dietary recalls for the parent study, 421 $(30.7 \%)$ were women of reproductive age (18-49 years old). We eliminated women who were currently pregnant ( $n$ 14), reported having cancer ( $n$ 13) or diabetes mellitus ( $n 41$ ), or were underweight ( $n 11$; due to concerns about drug abuse and/or other diseases that could affect diet and weight). We also eliminated women who did not consider themselves to be African-American or biracial including African-American ( $n$ 18; due to very small numbers of these participants), and women who did not have height and weight measured ( $n$ 5) or who were missing a dietary predictor or a covariate included in our regression models ( $n$ 18). Finally, seven women reported a mean daily energy intake below $2092 \mathrm{~kJ}$ ( $500 \mathrm{kcal}$ ) and fifteen reported a mean daily energy intake above $14644 \mathrm{~kJ}$ (3500 kcal); these extreme values were deemed implausible ${ }^{(47)}$ and these surveys were eliminated (7.0\% of our reduced sample). After all exclusions, 279 women remained for the current analysis.

\section{Measures of interest}

\section{$B M I$}

Interviewers measured height to the nearest $3 \mathrm{~mm}$ (1/8 in) using a carpenter's square (triangle) and a $2.44 \mathrm{~m}(8 \mathrm{ft})$ folding wooden ruler. Weight was measured using the SECA Robusta 813 digital scale to the nearest $45 \mathrm{~g}$ (1/10 lb). We calculated BMI as [weight $(\mathrm{kg})] /$ height $(\mathrm{m})]^{2}$ and categorized women as underweight $\left(<18.5 \mathrm{~kg} / \mathrm{m}^{2}\right)$, weight resilient, i.e. normal weight $\left(18.5-24.9 \mathrm{~kg} / \mathrm{m}^{2}\right)$, overweight $(25 \cdot 0$ $\left.29 \cdot 9 \mathrm{~kg} / \mathrm{m}^{2}\right)$ or obese $\left(\geq 30 \cdot 0 \mathrm{~kg} / \mathrm{m}^{2}\right)^{(48)}$.

\section{Eating behaviours}

Participants completed an interviewer-administered Automated Self-Administered 24-Hour (ASA-24) Dietary
Assessment Tool, beta version ${ }^{(49)}$, developed by the National Cancer Institute (Bethesda, MD, USA), which uses a modified version of the US Department of Agriculture's Automated Multiple-Pass Method and is designed to be self-administered ${ }^{(50)}$. The second recall was completed via telephone on a randomly selected day, $7-12 \mathrm{~d}$ after the in-person interview. The vast majority (94\%) of surveys were conducted in summer (52\%) or autumn ( $42 \%$ ), the periods of greatest availability of fresh produce in this geographic region. Dietary intake measures were based on the mean of the two recalls, unless participants completed only one $(7 \%$ of participants). The resulting dietary data were analysed by the ASA-24 program, which assigned food codes from the Food and Nutrient Database for Dietary Studies (version 1.0) developed and maintained by the US Department of Agriculture, and then analysed them using the MyPyramids Equivalents Database (version 1.0; now known as the 'Food Patterns Equivalents Database') ${ }^{(50)}$. Total cups of fruit (including 100\% fruit juice) and total cups of vegetables (including white potatoes and corn (excluding dried corn products and popcorn)) were calculated separately. F\&V quantities contained in mixed dishes were included in these totals. These two quantities were added together to get total cups of F\&V per day. The mean total cups of F\&V per day was calculated from the two dietary recalls and then recoded into a binary variable indicating whether the woman consumed 5 half-cup F\&V servings (i.e. 2.5 cups) per day (the well-known servings target advocated for by the ' 5 a Day for Better Health' campaign initiated by the National Cancer Institute and Produce for Better Health Foundation in 1991) or not. We also calculated the percentage meeting the latest Dietary Guidelines for Americans recommendation that reproductive-age women eat between 8 and 9 half-cup F\&V servings per day ( 2.5 cups of vegetables and 1.5-2 cups of fruit daily ${ }^{(51)}$ ) and calculated the mean total kilojoules/kilocalories consumed per day. To assess dieting behaviour, participants answered 'yes' or 'no' to the question, 'In the past month, have you been eating fewer calories to lose weight or to keep from gaining weight?'

Awareness of fruit and vegetable intake recommendations Awareness was assessed with an open-ended question which asked, 'How many portions of fruits and vegetables do doctors recommend that people eat each day?' Answers equal to or greater than 5 portions were considered correct.

\section{Self-efficacy}

Participants were asked a single question, 'If you wanted to, how sure are you that you can eat five or more fruits and vegetables on most days over the next year?' and answered with 'very sure', 'a little sure', 'not sure', 'a little unsure', 'very unsure' or 'don't know'. Those who answered 'very sure' were considered to have high self-efficacy. 


\section{Barriers to fruit and vegetable consumption}

With the data available from the parent study, we were able to assess barriers related to physical access, cost, concerns about waste, lack of time and food security. All participants in the present study lived in a food desert without a full-service grocery store; thus, to further conceptualize physical barriers, participants were asked if they drove their own car to go shopping and for the name and address of where they shopped for the majority of food on a regular basis. Addresses were geocoded using the 10.0 US Streets Address Locator within ArcGIS 10 (ESRI, Redlands, CA, USA). The distance between their residence and the store was calculated in miles and used as a continuous variable. They were also asked to respond to the following statement: 'It is easy to buy fruits and vegetables in my neighbourhood'. The Likert item responses were collapsed and those who responded 'strongly disagree' or 'disagree' were considered to have that barrier; those who responded 'neither agree nor disagree', 'agree' or 'strongly agree' were considered to not have this physical barrier. The following statements were used to assess barriers related to cost, concerns about waste and lack of time, in turn: 'Eating fruits and vegetables is difficult because they cost too much'; 'My household wastes too much food when I serve fruits and vegetables'; 'I don't have time to fix vegetables'. The Likert-item responses were collapsed to make the variables dichotomous. Those who responded 'strongly agree' or 'agree' were considered to have that barrier. Those who responded 'neither agree nor disagree', 'disagree' or 'strongly disagree' were considered to not have the barrier. Lastly, food security status was collected using the US Department of Agriculture's Household Food Security Module ${ }^{(52)}$. The raw scores were collapsed into 'low/very low security' and 'secure' categories for the current analysis, as directed by the US Department of Agriculture ${ }^{(53)}$.

\section{Other covariates}

The survey collected extensive information on several known sociodemographic confounders of the relationship between BMI and F\&V intake using validated items from the US Census/American Community Survey ${ }^{(54)}$, the Los Angeles Family and Neighborhood Study (LAFANS) ${ }^{(55)}$ and the Project on Human Development in Chicago Neighborhoods Community Survey (PHDCN) ${ }^{(56)}$. As income was the most frequently missing variable $(7 \%$ missing in our analysis sample), missing values were imputed for this variable for the parent study with the software IVEware in SAS macros version 0.2 (2009; Software Survey Methodology Program at the University of Michigan's Survey Research Center, Institute for Social Research, Ann Arbor, MI, USA). Adjusted income was computed as a ratio of imputed household income and number of individuals in the household. We selected potential confounders a priori from the survey data available with the guidance of our resilience/social ecological determinants of health behaviour framework. For consistency, we adjusted for the same set of confounders in all models. To avoid overfitting our models and to preserve degrees of freedom, we decided on a condensed, final set of confounders after observing the lack of variability across BMI categories for several potential confounders. Models were ultimately adjusted for age ( $<45$ years $v$. $\geq 45$ years), education (high-school graduate or less $v$. education beyond high school), employment (full-time $v$. other), parity (given birth to a live infant yes/no), lives alone (yes/no), physical activity (none $v$. any moderate or vigorous activity), per capita household income (continuous, logarithmically transformed) and total daily energy intake (continuous, logarithmically transformed, to remove extraneous variation in the measurement of F\&V intake) ${ }^{(57)}$. In order to preserve degrees of freedom and avoid overfitting, we opted to include the dichotomous 'lives alone' as a confounder capturing household make-up over several other options including: 'family type', 'has a child less than 6 years old in the household' and 'number of children in the household'. These variables were correlated with one another. Additional variables considered for adjustment but ultimately not used due to lack of apparent differences by BMI category included smoking, marital status, recent depression (assessed with the question, 'In the past 2 weeks, how often have you been feeling down, depressed or hopeless' from the Patient Health Questionnaire-2) ${ }^{(58)}$, perceived stress (using the four-item perceived stress scale score developed by Cohen et al. $)^{(59)}$ and receipt of Supplemental Nutrition Assistance Program benefits (SNAP; formerly known as food stamps). We did not consider controlling for self-reported health status because we expected people's responses to be directly tied to their weight status, in both a subjective and objective way; and we did not have a good objective measure of their health status.

\section{Statistical analysis}

We compared the sociodemographic and family characteristics of weight-resilient, overweight and obese women. We also compared their F\&V-related eating behaviours, awareness of recommendations, self-efficacy and barriers. Significant differences between groups were tested using $\chi^{2}$ tests or Student's $t$ tests for independent samples. Significant differences in counts were tested using Wilcoxon rank-sum tests. To generate prevalence ratios (PR) of being weight resilient compared with being overweight/obese, we first attempted to run log-binomial models, but encountered convergence issues. Poisson regression models with robust se from a sandwich variance estimator were used for all modelling instead, as they have been shown to be an acceptable alternative (even when applied to binomially distributed data and in small samples) ${ }^{(60-62)}$. We ran eleven separate regression models to estimate PR of being weight resilient compared with being overweight/obese for eleven dietary exposures, first 
unadjusted and then adjusted for confounders. The eleven exposures included eating $5 \mathrm{~F} \& \mathrm{~V}$ servings $/ \mathrm{d}$; awareness of F\&V intake recommendations; self-efficacy; three physical barriers (own a car, distance to grocery store used for most shopping, feel F\&V are easy to buy in neighbourhood); concern about cost as a barrier; concern about wasting food as a barrier; lack of time as a barrier; food security; and trying to consume less energy to lose weight or keep from gaining weight. We then added all eleven of these F\&V-related exposures to one model predicting weight resilience, and then we further adjusted this joint model for our confounders. Finally, we modelled the PR of consuming $\geq 5 \mathrm{~F} \& \mathrm{~V}$ servings/d with the other F\&V-related variables as predictors entered into one model, and then we further adjusted this joint model with the same set of confounders we used in our weight resiliency models.

Statistical significance was set at $P<0.05$ (two-sided). All analyses were conducted using the statistical software package StataMP version 14.0.

\section{Results}

Fifteen per cent of respondents were weight resilient, i.e. normal weight (mean BMI: 22.5 (sD 2.9 ) $\mathrm{kg} / \mathrm{m}^{2}$ ), $30 \%$ were overweight (mean BMI: 27.5 (SD 1.4$) \mathrm{kg} / \mathrm{m}^{2}$ ) and $55 \%$ were obese (mean BMI: 38.2 (sD 7.6$) \mathrm{kg} / \mathrm{m}^{2}$ ). Ninety-eight per cent of the respondents were born in the USA. Over $70 \%$ received SNAP benefits within the past year and $84 \%$ reported an annual household income under \$US 30000. Participants' mean age was 36 (SD 9.3) years. Table 1 shows sociodemographic characteristics and health behaviours by BMI group. While there was a wide range in terms of age, marital status, education and parity, these patterns did not vary significantly or meaningfully by BMI group. Compared with normal-weight women, overweight women were more likely to work full-time $(P=0 \cdot 01)$ and obese women had a slightly lower per capita income $(P=0 \cdot 06)$. Obese women were also more likely to live in a household with children compared with normal-weight women $(P=0.04)$ and were less likely to live alone compared with normal-weight women $(P<0 \cdot 001)$. Healthrelated factors were very similar across BMI groups; about half of the women smoked and a little over a third reported feeling depressed or hopeless several days or more over the past 2 weeks. Overall, the sample was very sedentary; however, the obese women reported the highest levels of physical activity. Normal-weight women were more likely to report being in 'excellent' or 'very good' health compared with overweight $(P=0.04)$ or obese $(P<0.001)$ women.

Overall, only a quarter of women reported eating $\geq 5$ $\mathrm{F} \& \mathrm{~V}$ servings/d. The median and interquartile range (IQR) of F\&V servings/d (1/2-cup equivalents) was $3 \cdot 1$ (IQR 3.2). Only $8 \%$ reported eating $\geq 8 \mathrm{~F} \& \mathrm{~V}$ servings/d, in accordance with the 2015 Dietary Guidelines for Americans.
Table 2 describes the differences in $\mathrm{F} \& \mathrm{~V}$ consumption and related factors by BMI. Normal-weight women were significantly more likely to consume $\geq 5 \mathrm{~F} \& \mathrm{~V}$ servings/d compared with overweight women $(P=0.03)$ and obese women $(P=0.02)$. The BMI groups were similar in terms of awareness of recommendations, self-efficacy and perceived barriers. Very few women correctly answered that you should eat $\geq 5 \mathrm{~F} \& \mathrm{~V}$ servings/d, but self-efficacy regarding F\&V intake was high across all BMI groups. All BMI groups reported similar physical barriers to F\&V consumption. Across BMI groups, only about one-third owned cars, most disagreed that it was easy to buy F\&V in their neighbourhood, and on average women were more than $3.2 \mathrm{~km}$ ( 2 miles) away from the location where they did most of their food shopping. Concern about cost was the most frequently reported barrier to F\&V consumption (36\% of the sample). However, in all BMI groups, the majority of women did not feel that concerns about cost, waste or time were barriers to F\&V consumption. The only significant difference by BMI was that obese women were more concerned about waste when they served F\&V compared with normal-weight women $(P=0.04)$, and this was borderline significant for overweight women $(P=0.06)$. Overall, more than one-third were classified as having low or very low food security, but food security did not differ significantly by BMI. Normal-weight women reported consuming more energy compared with the overweight and obese groups $(P=0.04)$, and, in general, women reporting that they were trying to consume less energy to lose weight did not consume significantly less energy, at least as reported on their dietary recall, compared with women not reporting dieting behaviour (median total daily energy intake: 6887 (IQR 4176) kJ (1646 (IQR 998) kcal) for non-dieters $v .6406$ (IQR 3653) kJ (1531 (IQR 873) kcal) for dieters, $P=0 \cdot 20$ ).

In unadjusted and adjusted models, consuming five fruits and vegetables daily was significantly associated with weight resilience (Table 3). Women consuming $\geq 5 \mathrm{~F} \& \mathrm{~V}$ servings/d were $94 \%$ more likely to be weight resilient compared with those consuming $<5$ F\&V servings/d $(P=0.02)$. In unadjusted models, the only other F\&V-related variable associated with weight resilience was perceiving waste as a barrier to $F \& V$ intake. This remained significant when adjusted for confounders; having concerns about wasting food when serving F\&V was associated with $71 \%$ less likelihood of being weight resilient compared with not having concerns about waste. When all the F\&V-related dietary predictors were entered in the same model, only eating $\geq 5 \mathrm{~F} \& \mathrm{~V}$ servings/d remained significantly associated with weight resilience $(P=0.03)$; this association remained but lost significance upon the addition of the confounders $(P=0 \cdot 08)$. Models comparing being weight resilient with being obese (i.e. eliminating the overweight women) produced very similar PR for these two factors, although these models had no significant findings due to the smaller sample (results not shown). 
Table 1 Sociodemographic characteristics and health status by BMI category among women aged 18-49 years $(n 279)$ from two low-income, predominantly African-American food deserts in Pittsburgh, Pennsylvania, USA, May-December 2011†

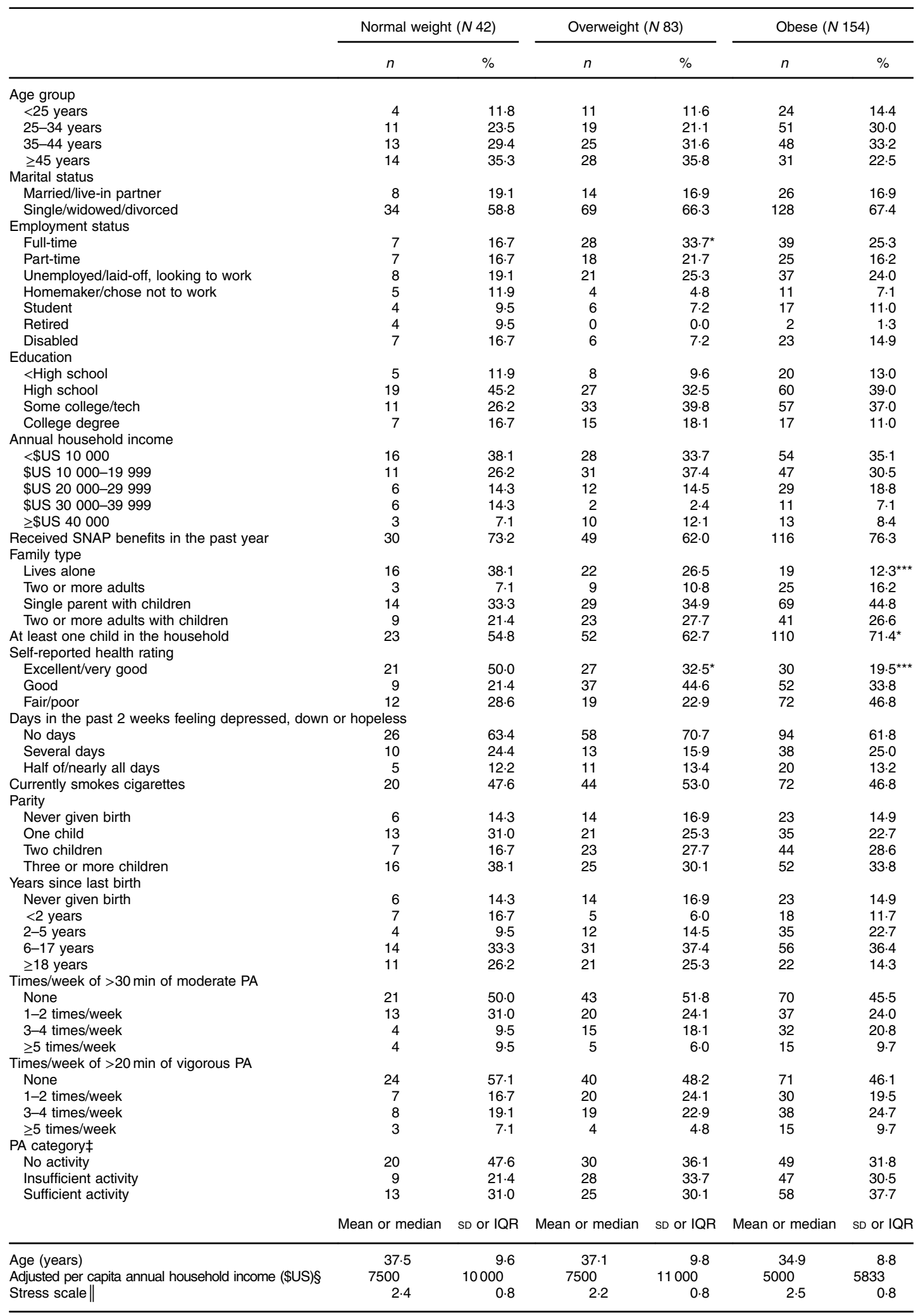

SNAP, Supplemental Nutrition Assistance Program; PA, physical activity; IQR, interquartile range.

${ }^{\star} P<0.05,{ }^{\star *} P<0.01,{ }^{* \star *} P<0.001$.

†Statistical testing was carried out, in turn, between normal-weight women and overweight women, and then normal-weight women and obese women. Statistical analysis was conducted by the $x^{2}$ test for categorical variables, Student's $t$ test for independent samples for Gaussian-distributed continuous variables, or Wilcoxon's rank-sum for non-Gaussian distributed continuous variables. Values significantly different from the normal-weight group are indicated with asterisks.

¥'Sufficient' PA defined as $\geq 5 \mathrm{~d} /$ week with $>30 \mathrm{~min}$ of moderate PA daily and/or $\geq 3 \mathrm{~d} /$ week with $>20$ min of vigorous PA daily.

$\S$ Median and IQR reported. Borderline significant at $P=0.06$, normal weight $v$. obese.

$\|$ On a scale of $1-5$, higher scores represent a higher stress level. 
Table 2 Fruit and vegetable-related eating behaviours, awareness, self-efficacy and barriers by BMl category among women aged 18-49 years ( $n$ 279) from two low-income, predominantly African-American food deserts in Pittsburgh, Pennsylvania, USA, May-December 2011†

\begin{tabular}{|c|c|c|c|c|c|c|}
\hline & \multicolumn{2}{|c|}{$\begin{array}{l}\text { Normal weight } \\
\quad(N \text { 42) }\end{array}$} & \multicolumn{2}{|c|}{$\begin{array}{l}\text { Overweight } \\
\quad(N 83)\end{array}$} & \multicolumn{2}{|c|}{$\begin{array}{l}\text { Obese } \\
(N 154)\end{array}$} \\
\hline & $n$ & $\%$ & $n$ & $\%$ & $n$ & $\%$ \\
\hline Consumption: $\geq 5$ F\&V servings/d $\ddagger$ & 17 & $40 \cdot 5$ & 18 & $21 \cdot 7^{\star}$ & 35 & $22 \cdot 7^{\star}$ \\
\hline $\begin{array}{l}\text { Awareness: Correctly responded that eating } \geq 5 \mathrm{~F} \& \mathrm{~V} \text { servings/d is recommended } \\
\text { Self-efficacy: How sure are you that you can eat } \geq 5 \mathrm{~F} \& \mathrm{~V} \text { servings on most days over } \\
\text { the next year? }\end{array}$ & 7 & $17 \cdot 1$ & 16 & $19 \cdot 3$ & 41 & $26 \cdot 8$ \\
\hline Very unsure & 4 & 9.5 & 4 & 4.8 & 9 & $5 \cdot 8$ \\
\hline A little unsure & 4 & 9.5 & 8 & $9 \cdot 6$ & 17 & 11.0 \\
\hline Not sure & 3 & $7 \cdot 1$ & 11 & $13 \cdot 3$ & 5 & $3 \cdot 3$ \\
\hline A little sure & 8 & $19 \cdot 1$ & 25 & $30 \cdot 1$ & 32 & $20 \cdot 8$ \\
\hline Very sure & 23 & $54 \cdot 8$ & 35 & $42 \cdot 2$ & 91 & $59 \cdot 1$ \\
\hline Physical barrier: Drive own vehicle to the store for major grocery shopping & 15 & $35 \cdot 7$ & 26 & $31 \cdot 3$ & 53 & 34.4 \\
\hline \multicolumn{7}{|l|}{ Physical barrier: It is easy to buy F\&V in my neighbourhood } \\
\hline Neither agree/disagree & 0 & 0.0 & 1 & $1 \cdot 2$ & 4 & $2 \cdot 6$ \\
\hline Disagree/strongly disagree & 33 & 78.6 & 65 & $78 \cdot 3$ & 104 & 67.5 \\
\hline \multicolumn{7}{|l|}{ Cost barrier: Eating $\geq 5 \mathrm{~F} \& \mathrm{~V}$ servings/d is difficult because they cost too much } \\
\hline Strongly agree/agree & 18 & $42 \cdot 9$ & 31 & 37.4 & 51 & $33 \cdot 1$ \\
\hline Neither agree/disagree & 3 & $7 \cdot 1$ & 3 & 3.6 & 7 & 4.6 \\
\hline Disagree/strongly disagree & 21 & $50 \cdot 0$ & 49 & 59.0 & 96 & $62 \cdot 3$ \\
\hline \multicolumn{7}{|l|}{ Waste barrier: I waste too much food when I serve F\&V } \\
\hline Strongly agree/agree & 3 & $7 \cdot 1$ & 18 & $21 \cdot 7$ & 35 & $22 \cdot 7^{*}$ \\
\hline Neither agree/disagree & 0 & 0.0 & 2 & $2 \cdot 4$ & 3 & $2 \cdot 0$ \\
\hline Disagree/strongly disagree & 39 & 92.9 & 63 & $75 \cdot 9$ & 116 & $7 \overline{5} \cdot 3$ \\
\hline \multicolumn{7}{|l|}{ Time barrier: I don't have time to fix vegetables } \\
\hline Strongly agree/agree & 1 & 2.4 & 4 & 4.8 & 6 & 3.9 \\
\hline Neither agree/disagree & 0 & 0.0 & 2 & 2.4 & 1 & 0.7 \\
\hline Disagree/strongly disagree & 41 & $97 \cdot 6$ & 77 & $92 \cdot 8$ & 147 & $95 \cdot 5$ \\
\hline Food security: Low/very low security & 14 & 33.3 & 33 & 39.8 & 60 & 39.0 \\
\hline \multirow{2}{*}{$\begin{array}{l}\text { Intention to diet: Tried to eat less energy in the last month to try to lose or keep from } \\
\text { gaining weight }\end{array}$} & 8 & $19 \cdot 1$ & 22 & $26 \cdot 5$ & 53 & $34 \cdot 4$ \\
\hline & Median & IQR & Median & IQR & Median & IQR \\
\hline F\&V servings consumed daily & 4.2 & 3.5 & $2 \cdot 9^{*}$ & 2.9 & $3 \cdot 0^{*}$ & 3.2 \\
\hline Total daily energy intake $(\mathrm{kJ} / \mathrm{d})$ & 7803 & 5577 & 6803 & 3883 & 6623 & 3644 \\
\hline Total daily energy intake $(\mathrm{kcal} / \mathrm{d})$ & 1865 & 1333 & 1626 & 928 & $1583^{*}$ & 871 \\
\hline Distance from the grocery store where most shopping is done $(\mathrm{km})$ & 3.7 & $2 \cdot 1$ & 3.5 & 2.6 & 3.9 & $6 \cdot 3$ \\
\hline Distance from the grocery store where most shopping is done (miles) & $2 \cdot 3$ & 1.3 & $2 \cdot 2$ & 1.6 & $2 \cdot 4$ & 3.9 \\
\hline
\end{tabular}

$\mathrm{F} \& \mathrm{~V}$, fruit and vegetable; IQR, interquartile range.

${ }^{*} P<0.05,{ }^{\star *} P<0.01,{ }^{* \star *} P<0.001$.

†Statistical testing was carried out, in turn, between normal-weight women and overweight women, and then normal-weight women and obese women. Statistical analysis was conducted by the $x^{2}$ test for categorical variables, Student's $t$ test for independent samples for Gaussian-distributed continuous variables, or Wilcoxon's rank-sum for non-Gaussian distributed continuous variables. Values significantly different from the normal-weight group are indicated with asterisks.

¥Servings were defined as $1 / 2$-cup equivalents of F\&V. Five servings daily equals 2.5 cups of $\mathrm{F} \& \mathrm{~V}$, the minimum recommended intake for an $8368 \mathrm{~kJ} / \mathrm{d}$ $(2000 \mathrm{kcal} / \mathrm{d})$ diet according to the 2010 Dietary Guidelines for Americans.

Table 3 Weight resilience predicted by fruit and vegetable-related eating behaviours, awareness and perceptions ( $n$ 279) among women aged 18-49 years ( $n$ 279) from two low-income, predominantly African-American food deserts in Pittsburgh, Pennsylvania, USA, May-December $2011 \dagger$

\begin{tabular}{|c|c|c|c|c|c|c|c|c|}
\hline \multirow[b]{2}{*}{ Exposure } & \multicolumn{2}{|c|}{ Unadjusted } & \multicolumn{2}{|c|}{$\begin{array}{l}\text { Adjusted for } \\
\text { confounders } \neq\end{array}$} & \multicolumn{2}{|c|}{$\begin{array}{c}\text { All F\&V-related } \\
\text { predictors§ in one } \\
\text { model }\end{array}$} & \multicolumn{2}{|c|}{$\begin{array}{l}\text { All F\&V-related } \\
\text { predictors plus } \\
\text { confounders }\end{array}$} \\
\hline & PR & $95 \% \mathrm{Cl}$ & PR & $95 \% \mathrm{Cl}$ & PR & $95 \% \mathrm{Cl}$ & PR & $95 \% \mathrm{Cl}$ \\
\hline $\begin{array}{l}\geq 5 \text { F\&V servings/d } \\
\text { Concerned about wasting food when serving F\&V }\end{array}$ & $\begin{array}{l}2.03 \\
0.31\end{array}$ & $\begin{array}{l}1.17,3.53 \\
0.10,0.96\end{array}$ & $\begin{array}{l}1.94 \\
0.29\end{array}$ & $\begin{array}{l}1 \cdot 10,3.43 \\
0.09,0.94\end{array}$ & $\begin{array}{l}1.90 \\
0.37\end{array}$ & $\begin{array}{l}1.08,3 \cdot 34 \\
0.11,1.20\end{array}$ & $\begin{array}{l}1.68 \\
0.35\end{array}$ & $\begin{array}{l}0.93,3.02 \\
0.10,1.23\end{array}$ \\
\hline
\end{tabular}

F\&V, fruit and vegetable; PR, prevalence ratio.

WWe ran eleven separate Poisson regression models predicting the PR of being normal weight compared with being overweight or obese associated with eleven F\&V-related dietary exposures. The exposures shown here were the only predictors out of the eleven that were significantly associated with weight resilience in bivariate, unadjusted analyses.

¥Adjusted for age category, education level, employment status, nulliparous, lives alone, physical activity level, mean total daily energy intake and per capita income.

$\S A l l$ eleven factors included eating $\geq 5$ F\&V servings/d; awareness of F\&V intake recommendations; self-efficacy; physical barriers (own a car, distance to grocery store used for most shopping, feel F\&V are easy to buy in neighbourhood); barriers related to cost, wasting food and lack of time; food security; and trying to consume less energy to lose weight or keep from gaining weight. 
Notably, across all models, the confounder 'lives alone' was consistently the strongest predictor of weight resilience. For example, in the adjusted model with $\geq 5 \mathrm{~F} \& \mathrm{~V}$ servings/d as the dietary exposure, women living alone were over twice as likely to be weight resilient compared with those who lived with other adults or with children $(\mathrm{PR}=2 \cdot 31 ; 95 \%$ CI 1.15, 4.64). There was no significant relationship between actual F\&V intake and self-efficacy, awareness of $\mathrm{F} \& \mathrm{~V}$ recommendations or most of the barriers, either overall or by BMI group, in bivariate analysis. Only driving one's own vehicle to store was borderline significantly associated with eating $\geq 5 \mathrm{~F} \& \mathrm{~V}$ servings/d in a model including all the $\mathrm{F} \& \mathrm{~V}$ predictors. However, the relationships went in the direction that one would expect to see for the vast majority of the predictors (see online supplementary material, Supplemental Table 1). Overall, only $31 \%$ of those who were aware of the 5 a day recommendation consumed $\geq 5$ servings/d. And only $29 \%$ of those who consumed $\geq 5$ servings/d were aware of the 5 a day recommendation.

\section{Discussion}

Examining the obesity epidemic among low-income communities through the lens of a weight resilience framework holds promise for elucidating the complex relationships between the food environment, BMI, and dietary behaviours and attitudes. Because instituting changes to food desert environments can be resourceintensive, identifying and acting on protective factors that already exist within a community may lead to more efficient, targeted community-wide interventions. A better understanding of how weight-resilient African-American women of reproductive age are able to withstand these neighbourhood pressures is needed to better target community-wide interventions to lower BMI in this highrisk group. The present study is the first to examine weight resilience in a homogeneous neighbourhood sample of low-income, African-American women of reproductive age in the USA. It is larger than similar studies looking at motivators of and barriers to healthy eating in this population, and it collected rich data on F\&V-related eating attitudes, knowledge and behaviours, and related confounders in a low-income African-American female population. Owing to the fact that the parent study was focused on eating behaviours and access to healthy foods, data on many non-food-related factors potentially contributing to weight resilience, such as sleep patterns, more extensive measures of physical activity and genetics/ weight status of family members, were not collected. Thus, our investigation was firmly centred around F\&V's relationship to weight resilience.

As expected, most of the women in these two neighbourhoods were overweight or obese. Only 15\% of women were weight resilient, speaking to the great difficulty of resisting the effects of living in a low-income food desert. Notably, there were very few demographic differences between the weight-resilient and overweight and obese women. Income, smoking, education, stress and depression, which are typically associated with both BMI and F\&V intake, did not vary substantially across BMI. Only $25 \%$ of our sample reported consuming at least five, $1 / 2$-cup servings of $F \& V$ daily and only $8 \%$ reported consuming at least eight, $1 / 2$-cup servings daily, which is lower than the latest national median intakes reported $^{(27,63)}$. We found that consuming $\geq 5 \mathrm{~F} \& \mathrm{~V}$ servings/d was associated with weight resilience, even after controlling for several known confounders. We also found that having concerns about wasting food when serving F\&V was negatively associated with weight resilience. However, awareness of recommended F\&V intake was low across the board and did not vary by weight resilience. Moreover, self-efficacy regarding ability to eat the recommended F\&V servings was remarkably high in all BMI groups and the majority did not report many perceived barriers to $F \& V$ consumption, but these factors were not related to weight resilience. In a joint model predicting eating $\geq 5 \mathrm{~F} \& \mathrm{~V}$ servings/d, driving one's own vehicle to the store for grocery shopping was the only F\&V-related variable that was significant, suggesting that perhaps F\&V are too inconvenient and bulky to transport otherwise. The inconsistency of results between actual F\&V intake and awareness of recommendations and selfefficacy (which are presumed to precede intake in the stages of change model of behavioural theory) suggests that $F \& V$ intake in this population may be influenced by factors other than the goal of healthy eating, or it may be evidence that these two communities have collectively moved through the stages of change and are primed to take action to increase consumption once other, nonattitudinal barriers are removed. Physical barriers to F\&V intake were commonly reported among all women who all lived in a known food desert and, aside from vehicle ownership, were not related to $\mathrm{F} \& \mathrm{~V}$ intake or weight resilience. Somewhat surprisingly, our group of weightresilient women were older than the overweight and obese women and more likely to live alone. This hints at how children and partners in the household may influence women's food choices and weight. Focus group studies conducted with low-income women suggest that children's and partners' food preferences play a large role in what they decide to prepare and serve, and are a common barrier to healthier eating ${ }^{(64-66)}$. There could also be generational differences at play in women's ability to cook and efficiently use F\&V; however, the effect of having a partner/children living in the household cannot be separated easily from age in our sample due to the fact that women who lived alone were older.

The present study adds to the evidence that higher F\&V intake is associated with a lower $\mathrm{BMI}^{(19-21)}$ and more effectively controls for the effect of socio-economic status than previous studies. The exact mechanism behind this inverse association between BMI and F\&V intake remains 
unclear, but hypotheses include F\&V displacing energydense foods ${ }^{(17)}$, effects on satiety either through fibre or other unidentified $\mathrm{F} \& \mathrm{~V}$ properties that lead to lower overall energy intake ${ }^{(67)}$, or regulation of postprandial glycaemic response, with the possibility that long-term consumption patterns could lead to metabolic differences between normal-weight and overweight/obese women ${ }^{(68)}$. However, it is also possible that $\mathrm{F} \& \mathrm{~V}$ intake may simply be a proxy for overall diet quality ${ }^{(69)}$ or an undetermined behavioural characteristic that is protective against weight gain and hard to measure with survey questions, such as skill in cooking, or being organized and motivated, as it is arguably more difficult to store, prepare and consume fresh F\&V than packaged convenience items. The findings of the present sub-study echo the findings of the larger PHRESH study showing little association between access to grocery stores and $\mathrm{F} \& \mathrm{~V}$ intake and $\mathrm{BMI}^{(44)}$. The larger study found that there were plenty of $F \& V$ available at the places where people were already doing the majority of their food shopping, suggesting that increasing access to a full-service grocery store would alone do little to increase purchasing of F\&V. Having a grocery store in the neighbourhood would cut the distance that people need to travel, but they would still need to transport bulky F\&V purchases home. Without access to a vehicle, the distance between store and home may still be considered too far for some women. Several other recent studies have found similar results, suggesting that environment plays a lesser role than originally hypothesized in regard to diet ${ }^{(44,45,70,71)}$ and that building fullservice grocery stores in food deserts may not prove to be the magic bullet to improving F\&V intake.

Our results are consistent with the US study of weight resilience in low-income female African-American adolescents $^{(21)}$, which found that higher F\&V intake was related to maintaining a normal weight. Notably, that study also found that higher self-efficacy was associated with being obese, which mirrors our own findings. This association between high self-efficacy and obesity ${ }^{(72-74)}$ and the lack of relationship between awareness of nutritional recommendations and BMI have been seen in other studies conducted in low-income, African-American samples ${ }^{(74,75)}$. However, the lack of perceived barriers reported by our sample is surprising. Other studies, predominantly small focus groups, have reported lack of time, cost and waste as being significant barriers to F\&V intake in low-income, African-American populations ${ }^{(39,40)}$. The other large comprehensive community study of weight resilience among women in socially disadvantaged communities in Australia ${ }^{(24)}$ did not find a relationship between F\&V intake and BMI, but it did find that higher self-efficacy and higher nutrition knowledge were associated with consumption of low-energy-dense foods, including F\&V. These discrepant findings could be due in part to cultural differences between low-income communities in the USA and Australia, or to differences in access to $\mathrm{F} \& \mathrm{~V}$ if they are desired. Additionally, the US study was a convenience sample of patients recruited from one adolescent health clinic in Detroit, while the Australian study was a larger random sample of many disparate disadvantaged neighbourhoods throughout Victoria, Australia, and it had a relatively low response rate of $45 \%$. Neither sample was as homogeneous and controlled as our own neighbourhood sample. The Australian study also used structural equation modelling, a group of predictors related to social support for healthy eating and extensive data on the social-ecological determinants of physical activity, while ours was focused only on F\&V-related food factors. It is possible that the effect of $F \& V$ intake on weight resilience is mitigated as more extensive F\&Vrelated interpersonal/social factors and physical activity variables are added to the model. None the less, together with other US study findings, our analysis adds to the literature suggesting that additional interventions that attempt to influence knowledge, self-efficacy and perceptions of barriers will likely do little to actually increase F\&V intake or reduce BMI in this particular population because they are already getting these messages and they are not predictive of intake.

There are limitations that must be considered. These cross-sectional data do not allow us to estimate a causal effect of any of the dietary predictors on BMI. As the present study was a sub-analysis of the larger PHRESH study which was not specifically designed to look at the issue of weight resilience in this particular population, our sample size is small. Participants were randomly selected to participate based on geographic location within the neighbourhood and the overall response rate of households was $67 \%$, but the specific response rate of the reproductive-aged women is unknown. There was selection bias; those who did enrol were older, less likely to have children, and more likely to be retired or disabled than expected, likely because they were simply more likely to be home when the study recruiter visited the residence to enrol them. The survey data were collected in women's homes by trained interviewers who lived in the surveyed neighbourhoods, and although the study was designed this way to reduce social desirability bias, having local data collectors could have also introduced bias if woman felt pressured to answer according to the neighbourhood status quo. Measurement error of dietary intake is always of concern ${ }^{(76)}$, and under-reporting, which is already a concern with $24 \mathrm{~h}$ dietary recalls, has been shown to be particularly problematic in obese, female, low-income, nonHispanic black populations, such as this one ${ }^{(77,78)}$. However, $93 \%$ of our participants contributed two days of dietary recall data collected using the US Department of Agriculture's validated Automated Multiple-Pass Method, which is the method currently thought to induce the least amount of systematic bias to dietary data ${ }^{(78,79)}$. Additionally, while energy and fat are frequently under-reported, it has been suggested that reporting of F\&V intake is less likely to be underestimated ${ }^{(76,80)}$, and dietary measurement error 
usually tends to bias associations to towards the null, suggesting that the relationship between BMI and F\&V intake in this population may be even stronger than it appears in our models ${ }^{(77)}$. We did not have information on the weight status of friends and relatives, so we do not have information on either intrafamily genetic or cultural pressures contributing to obesity. Physical activity, which is generally thought to be a strong predictor of weight status, was entirely self-reported and the chance of misclassification is high. There are several potential confounders that could be independently associated with both BMI and F\&V eating patterns that were not collected, including a history of disordered eating behaviours (e.g. binge eating and purging and emotional eating), psychological disorders, drug or alcohol dependency, and breast-feeding. Participants were not asked about participation in organized weight management programmes or whether they were on special diets for an existing health condition; however, we did exclude those with cancer and diabetes, which captured some of these women. Participants were asked about whether they tried to eat less energy over the past month to lose weight or keep from gaining weight. While these self-reported dieters did report eating slightly less energy, we do not know for sure if they actually did eat less energy or just reported eating slightly less. It is likely that this variable is a better measure of 'intentions to diet' than actually successfully consuming less energy. While we used validated questions regarding the attitudinal dietary predictors, there was likely measurement error, which may explain the lack of significant findings in these models. We did not have information on how long women had been at their current weight, and thus we cannot speak to the weight resilience of women over time. Finally, as this was a homogeneous sample of mostly low-income African-American women of reproductive age living in an urban setting, the generalizability of the findings is limited to similar populations. Even within our all-female, narrowly geographically defined population, there are 'micro-populations' of women (with children $v$. no children, employed $v$. disabled, etc.) who likely experience access to and intake of F\&V very differently in their daily lives.

Our findings in this low-income community of AfricanAmerican women of reproductive age suggest that efforts to increase awareness of $\mathrm{F} \& \mathrm{~V}$ recommendations, increase self-efficacy regarding $F \& V$ intake or decrease the perception of barriers to $\mathrm{F} \& \mathrm{~V}$ intake are unlikely to play a role in weight resilience. A focus on convenient and concrete steps to increase access to affordable and desirable F\&V options in this population may have greater potential for increasing intake, and ultimately fostering weight resilience, than attempts to change attitudes and perceptions, which are already positive. For instance, gleaning programmes that funnel fresh produce into food pantries and allowing for use of SNAP vouchers at farmers' markets may have more impact than the construction of full-service grocery stores in the neighbourhood, as worries about the cost of $F \& V$ is a barrier. A better understanding of the psychosocial factors that lead to differential $F \& V$ intake among African-American women of reproductive age, such as differences in taste preferences, motivation to plan meals and cooking skills to prepare meals containing F\&V, is needed. Finally, the role that children and other adults residing in the household play in influencing a woman's food purchasing and consumption decisions deserves further study and may be the key to increasing F\&V consumption in this particular reproductive-aged population.

\section{Acknowledgements}

Acknowledgements: The authors wish to sincerely thank Stephanie Lonsinger and Elizabeth Steiner who provided administrative assistance for all aspects of the study, through its implementation to analyses. These analyses would not have been possible without La'Vette Wagner, Field Coordinator of the Pittsburgh Hill/Homewood Research on Eating, Shopping and Health study, and the eighteen resident data collectors. Special thanks to Robin Beckman for her preparation of the $24 \mathrm{~h}$ dietary recall data. Financial support: This research was supported by a grant from the National Institutes of Health (Bethesda, MD, USA; number R01CA149105) and a contract with the Centers for Disease Control and Prevention (Atlanta, GA, USA; \#200-2010-M-34201). These funders had no role in the design, analysis or writing of this article. Conflict of interest: S.M.P., L.M.B. and T.D. have no conflicts of interest to disclose. Authorship: S.M.P. took primary responsibility for conceptualizing the research, analysing the data, writing the manuscript and determining its final content; L.M.B. conceptualized analyses and provided feedback and revisions on the manuscript; T.D. developed, designed and coordinated the parent study and provided feedback and revisions on the manuscript. All authors read and approved the final manuscript. Etbics of buman subject participation: The study protocol was approved by the RAND Human Subjects Protection Committee (HSPC).

\section{Supplementary material}

To view supplementary material for this article, please visit https://doi.org/10.1017/S1368980017002488

\section{References}

1. Larson NI, Story MT \& Nelson MC (2009) Neighborhood environments: disparities in access to healthy foods in the US. Am J Prev Med 36, 74-81.e10.

2. Walker RE, Keane CR \& Burke JG (2010) Disparities and access to healthy food in the United States: a review of food deserts literature. Health Place 16, 876-884.

3. Ball K \& Crawford D (2006) Socio-economic factors in obesity: a case of slim chance in a fat world? Asia Pacific J Clin Nutr 15, 15-20. 
4. Ball KD \& Dollman J (2010) Physical activity, healthy eating and obesity prevention: understanding and promoting 'resilience' amongst socioeconomically disadvantaged groups. Australas Epidmiol 17, 16-17.

5. Flegal KM, Kruszon-Moran D, Carroll MD et al. (2016) Trends in obesity among adults in the United States, 2005 to 2014. JAMA 315, 2284-2291.

6. Kulie T, Slattengren A, Redmer J et al. (2011) Obesity and women's health: an evidence-based review. J Am Board Fam Med 24, 75-85.

7. Lash MM \& Armstrong A (2009) Impact of obesity on women's health. Fertil Steril 91, 1712-1716.

8. Robinson J \& Burke A (2013) Obesity and hormonal contraceptive efficacy. Womens Health (Lond) 9, 453-466.

9. Siega-Riz A \& King J, American Dietetic Association, et al. (2009) Position of the American Dietetic Association and American Society for Nutrition: Obesity, reproduction, and pregnancy outcomes. J Am Diet Assoc 109, 918-927.

10. Honein MA, Devine O, Sharma AJ et al. (2013) Modeling the potential public health impact of prepregnancy obesity on adverse fetal and infant outcomes. Obesity (Silver Spring) 21, 1276-1283.

11. Bodnar LM, Siminerio LL, Himes KP et al. (2016) Maternal obesity and gestational weight gain are risk factors for infant death. Obesity (Silver Spring) 24, 490-498.

12. Walker L, Timmerman G, Sterling B et al. (2004) Do lowincome women attain their pre-pregnant weight by the 6th week of postpartum? Ethn Dis 14, 119-126.

13. Smith D, Lewis C, Caveny J et al. (1994) Longitudinal changes in adiposity associated with pregnancy - the CARDIA study. JAMA 271, 1747-1751.

14. Pugh SJ, Richardson GA, Hutcheon JA et al. (2015) Maternal obesity and excessive gestational weight gain are associated with components of child cognition. J Nutr 145, 2562-2569.

15. Roberts VHJ, Frias AE \& Grove KL (2015) Impact of maternal obesity on fetal programming of cardiovascular disease. Physiology 30, 224-231.

16. Flagg LA, Sen B, Kilgore ML et al. (2014) The influence of gender, age, education and household size on meal preparation and food shopping responsibilities. Public Health Nutr 17, 2061-2070.

17. Rolls B, Ello-Martin J \& Tohill B (2004) What can intervention studies tell us about the relationship between fruit and vegetable consumption and weight management? Nutr Rev 62, $1-17$.

18. He F, Nowson C, Lucas M et al. (2007) Increased consumption of fruit and vegetables is related to a reduced risk of coronary heart disease: meta-analysis of cohort studies. J Hum Hypertens 21, 717-728.

19. Heo M, Kim RS, Wylie-Rosett J et al. (2011) Inverse association between fruit and vegetable intake and BMI even after controlling for demographic, socioeconomic and lifestyle factors. Obes Facts $\mathbf{4}, 449-455$.

20. Azagba S \& Sharaf M (2012) Fruit and vegetable consumption and body mass index: a quantile regression approach. J Prim Care Community Health 3, 210-220.

21. Brogan K, Idalski Carcone A, Jen KL et al. (2012) Factors associated with weight resilience in obesogenic environments in female African-American adolescents. J Acad Nutr Diet 112, 718-724.

22. Tohill BC, Seymour JD, Serdula M et al. (2004) What epidemiologic studies tell us about the relationship between fruit and vegetable consumption and body weight. Nutr Rev 62, 365-374

23. Ledoux TA, Hingle MD \& Baranowski T (2011) Relationship of fruit and vegetable intake with adiposity: a systematic review. Obes Rev 12, e143-e150.

24. Ball K, Abbott G, Cleland V et al. (2012) Resilience to obesity among socioeconomically disadvantaged women: the READI study. Int J Obes (Lond) 36, 855-865.
25. Public Health Service (1990) Healthy People 2000: National Health Promotion and Disease Prevention Objectives. DHHS Publication no. (PHS) 90-50212. Washington, DC: US Department of Health and Human Services.

26. Centers for Disease Control and Prevention (2013) State Indicator Report on Fruits and Vegetables, 2013. Atlanta, GA: US Department of Health and Human Services.

27. Moore LV \& Thompson FE (2015) Adults meeting fruit and vegetable intake recommendations - United States, 2013. MMWR Morb Mortal Wkly Rep 64, 710-713.

28. Li R, Serdula M, Bland S et al. (2000) Trends in fruit and vegetable consumption among adults in 16 US states: behavioral risk factor surveillance system, 1990-1996. Am J Public Health 90, 777-781.

29. Darmon N \& Drewnowski A (2008) Does social class predict diet quality? Am J Clin Nutr 87, 1107-1117.

30. Kirkpatrick SI, Dodd KW, Reedy J et al. (2012) Income and race/ethnicity are associated with adherence to food-based dietary guidance among US adults and children. J Acad Nutr Diet 112, 624-635.e626.

31. Dubowitz T, Heron M, Bird CE et al. (2008) Neighborhood socioeconomic status and fruit and vegetable intake among whites, blacks, and Mexican Americans in the United States. Am J Clin Nutr 87, 1883-1891.

32. Davison KK \& Birch LL (2001) Childhood overweight: a contextual model and recommendations for future research. Obes Rev 2, 159-171.

33. Baranowski T, Cullen KW, Nicklas T et al. (2003) Are current health behavioral change models helpful in guiding prevention of weight gain efforts? Obes Res 11, Suppl., 23S-43S.

34. Garmezy N (1985) Stress-resistant children: the search for protective factors. In Recent Research in Developmental Pathopathology: Journal of Child Psychology and Psychiatry Book Supplement \#4, pp. 213-233 [JE Stevenson, editor]. Oxford: Blackwell Scientific.

35. Neville CE, McKinley MC, Draffin CR et al. (2015) Participating in a fruit and vegetable intervention trial improves longer term fruit and vegetable consumption and barriers to fruit and vegetable consumption: a follow-up of the ADIT study. Int J Behav Nutr Phys Act 12, 158.

36. Watters JL, Satia JA \& Galanko JA (2007) Associations of psychosocial factors with fruit and vegetable intake among African-Americans. Public Health Nutr 10, 701-711.

37. Morel L'Horset A, Schoenthaler A, Chaplin W et al. (2015) Changes in self-efficacy and fruit and vegetable intake in the FAITH trial. FASEB J 29, 1 Suppl., 584.6.

38. Luszczynska A, Tryburcy M \& Schwarzer R (2007) Improving fruit and vegetable consumption: a self-efficacy intervention compared with a combined self-efficacy and planning intervention. Health Educ Res 22, 630-638.

39. Chang M-W, Nitzke S, Guilford E et al. (2008) Motivators and barriers to healthful eating and physical activity among low-income overweight and obese mothers. J Am Diet Assoc 108, 1023-1028.

40. Barnes A, Goodrick GK, Pavlik V et al. (2007) Weight loss maintenance in African-American women: focus group results and questionnaire development. J Gen Intern Med 22, 915-922.

41. Lucan SC, Barg FK \& Long JA (2010) Promoters and barriers to fruit, vegetable, and fast-food consumption among urban, low-income African Americans - a qualitative approach. Am J Public Health 100, 631-635.

42. Thomson C (2011) Fruits, Vegetables, and Behavior Change: A Scientific Overview, 2011. Hockessin, DE: Produce for Better Health Foundation; available at https:// pbhfoundation.org/pdfs/about/res/pbh_res/PBH_Behavior_ Change_Review.pdf

43. Dubowitz T, Ncube C, Leuschner K et al. (2015) A natural experiment opportunity in two low-income urban food desert communities: research design, community 
engagement methods, and baseline results. Health Educ Behav 42, 1 Suppl., 87S-96S.

44. Dubowitz T, Zenk S, Ghosh-Dastidar B et al. (2015) Healthy food access for urban food desert residents: examination of the food environment, food purchasing practices, diet and BMI. Public Health Nutr 18, 2220-2230.

45. Dubowitz T, Ghosh-Dastidar M, Cohen DA et al. (2015) Diet and perceptions change with supermarket introduction in a food desert, but not because of supermarket use. Health Aff (Millwood) 34, 1858-1868.

46. Economic Research Service, US Department of Agriculture (2009) Food Access Research Atlas, Archived Food Dessert Locator Documentation. https://www.ers.usda.gov/dataproducts/food-access-research-atlas/download-the-data/ \#Archived Versions (accessed September 2017).

47. Rhee JJ, Sampson L, Cho E et al. (2015) Comparison of methods to account for implausible reporting of energy intake in epidemiologic studies. Am J Epidemiol 181, 225-233.

48. World Health Organization (2000) Obesity: Preventing and Managing the Global Epidemic. Report of a WHO Consultation. WHO Technical Report Series no. 894. Geneva: WHO.

49. Subar A, Kirkpatrick S, Mitt lB et al. (2012) The automated self-administered 24-hour dietary recall (ASA24): a resource for researchers, clinicians, and educators from the National Cancer Institute. J Acad Nutr Diet 112, 1134-1137.

50. National Cancer Institute (2017) Automated SelfAdministered 24-Hour Dietary Assessment Tool. https:// epi.grants.cancer.gov/asa24/ (accessed July 2017).

51. US Department of Health and Human Services \& US Department of Agriculture (2015) 2015-2020 Dietary Guidelines for Americans, 8th ed. Washington, DC: US Government Printing Office; available at http://health.gov/ dietaryguidelines/2015/guidelines/

52. US Department of Agriculture, Food and Nutrition Service (2000) Guide to Measuring Household Food Security (Revised 2000). https://www.fns.usda.gov/guide-measuringhousehold-food-security-revised-2000 (accessed March 2017).

53. US Department of Agriculture, Economic Research Service (2000) Food Security in the US, Survey Tools. https://www. ers.usda.gov/topics/food-nutrition-assistance/food-securityin-the-us/survey-tools/\#guide (accessed March 2017).

54. US Census Bureau (2010) American Community Survey: Documentation. https://www.census.gov/programs-surveys/ acs/methodology.html (accessed March 2017).

55. Sastry N, Ghosh-Dastidar B, Adams J et al. (2006) The Design of a Multilevel Survey of Children, Families, and Communities: The Los Angeles Family and Neighborbood Survey. Santa Monica, CA: RAND Corporation.

56. Inter-university Consortium for Political and Social Research (n.d.) Project on Human Development in Chicago Neighborhoods (PHDCN): Master File, Wave 3, 2000-2002 (ICPSR 13668). http://www.icpsr.umich.edu/icpsrweb/ PHDCN/studies/13668 (accessed September 2017).

57. Willett WC, Howe GR \& Kushi LH (1997) Adjustment for total energy intake in epidemiologic studies. Am J Clin Nutr 65, 4 Suppl., 1220S-1228S.

58. Kroenke K, Spitzer RL \& Williams JB (2003) The Patient Health Questionnaire-2: validity of a two-item depression screener. Med Care 41, 1284-1292.

59. Cohen S, Kamarck T \& Mermelstein R (1983) A global measure of perceived stress. J Health Soc Behav 24, 385-396.

60. Zou G (2004) A modified Poisson regression approach to prospective studies with binary data. Am J Epidemiol 159 , 702-706.
61. Barros AJ \& Hirakata VN (2003) Alternatives for logistic regression in cross-sectional studies: an empirical comparison of models that directly estimate the prevalence ratio. $B M C$ Med Res Methodol 3, 21.

62. Petersen MR \& Deddens JA (2008) A comparison of two methods for estimating prevalence ratios. BMC Med Res Methodol 8, 9 .

63. Kimmons J, Gillespie C, Seymour J et al. (2009) Fruit and vegetable intake among adolescents and adults in the United States: percentage meeting individualized recommendations. Medscape J Med 11, 26.

64. Inglis V, Ball K \& Crawford D (2005) Why do women of low socioeconomic status have poorer dietary behaviours than women of higher socioeconomic status? A qualitative exploration. Appetite 45, 334-343.

65. Lawrence W, Skinner C, Haslam C et al. (2009) Why women of lower educational attainment struggle to make healthier food choices: the importance of psychological and social factors. Psychol Health 24, 1003-1020.

66. James D (2004) Factors influencing food choices, dietary intake, and nutrition-related attitudes among African Americans: application of a culturally sensitive model. Ethn Health 9, 349-367.

67. Flood-Obbagy JE \& Rolls BJ (2009) The effect of fruit in different forms on energy intake and satiety at a meal. Appetite 52, 416-422.

68. Livesey G, Taylor R, Hulshof $\mathrm{T}$ et al. (2008) Glycemic response and health - a systematic review and meta-analysis: relations between dietary glycemic properties and health outcomes. Am J Clin Nutr 87, issue 1, 258S-268S.

69. Garriguet D (2009) Diet quality in Canada. Health Rep 20, $41-52$.

70. Thornton LE, Lamb KE, Tseng M et al. (2015) Does food store access modify associations between intrapersonal factors and fruit and vegetable consumption? Eur J Clin Nutr 69, 902-906.

71. Cummins S, Flint E \& Matthews SA (2014) New neighborhood grocery store increased awareness of food access but did not alter dietary habits or obesity. Health Aff (Millwood) 33, 283-291.

72. Nigg C, Borrelli B, Maddock J et al. (2008) A theory of physical activity maintenance. Appl Psychol 57, 544-560.

73. Martin P, Dutton G \& Brantley P (2004) Self-efficacy as a predictor of weight change in African-American women. Obes Res 12, 646-651.

74. Acheampong I \& Haldeman L (2013) Are nutrition knowledge, attitudes, and beliefs associated with obesity among low-income Hispanic and African American women caretakers? J Obes 2013, 123901.

75. Gordon-Larson P (2001) Obesity-related knowledge, attitudes, and behaviors in obese and non-obese urban Philadelphia female adolescents. Obes Res 9, 112-118.

76. Subar AF, Freedman LS, Tooze JA et al. (2015) Addressing current criticism regarding the value of self-report dietary data. J Nutr 145, 2639-2645.

77. Murakami K \& Livingstone MBE (2015) Prevalence and characteristics of misreporting of energy intake in US adults: NHANES 2003-2012. Br J Nutr 114, 1294-1303.

78. Freedman LS, Commins JM, Moler JE et al. (2014) Pooled results from 5 validation studies of dietary self-report instruments using recovery biomarkers for energy and protein intake. Am J Epidemiol 180, 172-188.

79. Subar AF, Kipnis V, Troiano RP et al. (2003) Using intake biomarkers to evaluate the extent of dietary misreporting in a large sample of adults: the OPEN study. Am J Epidemiol 158, $1-13$

80. Johnson RK (2002) Dietary intake - how do we measure what people are really eating? Obes Res 10, Suppl. 1, 63S-68S. 